\title{
Signatures of co-evolutionary host- pathogen interactions in the genome of the entomopathogenic nematode Steinernema carpocapsae
}

\author{
Mitzi Flores-Ponce ${ }^{1}$, Miguel Vallebueno-Estrada' ${ }^{1}$ Eduardo González-Orozco ${ }^{1}$, Hilda E. Ramos-Aboites ${ }^{1}$,
}

J. Noé García-Chávez , Nelson Simões² and Rafael Montiel ${ }^{1 *}$ (D)

\begin{abstract}
Background: The entomopathogenic nematode Steinernema carpocapsae has been used worldwide as a biocontrol agent for insect pests, making it an interesting model for understanding parasite-host interactions. Two models propose that these interactions are co-evolutionary processes in such a way that equilibrium is never reached. In one model, known as "arms race", new alleles in relevant genes are fixed in both host and pathogens by directional positive selection, producing recurrent and alternating selective sweeps. In the other model, known as"trench warfare", persistent dynamic fluctuations in allele frequencies are sustained by balancing selection. There are some examples of genes evolving according to both models, however, it is not clear to what extent these interactions might alter genome-level evolutionary patterns and intraspecific diversity. Here we investigate some of these aspects by studying genomic variation in S. carpocapsae and other pathogenic and free-living nematodes from phylogenetic clades IV and V.
\end{abstract}

Results: To look for signatures of an arms-race dynamic, we conducted massive scans to detect directional positive selection in interspecific data. In free-living nematodes, we detected a significantly higher proportion of genes with sites under positive selection than in parasitic nematodes. However, in these genes, we found more enriched Gene Ontology terms in parasites. To detect possible effects of dynamic polymorphisms interactions we looked for signatures of balancing selection in intraspecific genomic data. The observed distribution of Tajima's D values in $S$. carpocapsae was more skewed to positive values and significantly different from the observed distribution in the free-living Caenorhabditis briggsae. Also, the proportion of significant positive values of Tajima's D was elevated in genes that were differentially expressed after induction with insect tissues as compared to both non-differentially expressed genes and the global scan.

Conclusions: Our study provides a first portrait of the effects that lifestyle might have in shaping the patterns of selection at the genomic level. An arms-race between hosts and pathogens seems to be affecting specific genetic functions but not necessarily increasing the number of positively selected genes. Trench warfare dynamics seem to be acting more generally in the genome, likely focusing on genes responding to the interaction, rather than targeting specific genetic functions.

Keywords: Arms race, Red Queen, Trench warfare, Positive selection, Balancing selection, Genomic scans, dN/dS, Tajima's D

\footnotetext{
* Correspondence: rafael.montiel@cinvestav.mx

'Laboratorio Nacional de Genómica para la Biodiversidad, Unidad de

Genómica Avanzada, Centro de Investigación y de Estudios Avanzados del

Instituto Politécnico Nacional, Km 9.6 Libramiento Norte Carretera Irapuato -

León, Irapuato, Guanajuato, Mexico

Full list of author information is available at the end of the article
} 


\section{Background}

Nematodes are the most abundant type of animals on earth in terms of the number of individuals, being an ancient and diverse group [1]. Their diversity and abundance are the result of their extraordinary ability to adapt, small size, resistant cuticle, and simple body plan [2]. Nematodes have independently evolved parasitism several times in all major clades [3-5] and it has been proposed that understanding the genomic adaptations to parasitism in one clade could give insight into how parasitism has evolved across the phylum [5, 6]. Entomopathogenic nematodes (EPNs) represent an interesting group of parasitic nematodes, comprising the genera Heterorhabditis and Steinernema, which are lethal parasites of insects capable of infecting and killing a wide range of insects. Invertebrate parasitism evolved independently in these genera, which belong to different clades of the Nematoda phylogeny (clades V and IV, respectively [3]), thus representing an interesting case of convergent evolution [7]. Steinernema carpocapsae is one of the most well-known species of EPNs. It has been used worldwide as a biocontrol agent for insect pests and represents an interesting model to understanding parasite-host interactions $[8,9]$. Sharing a symbiotic association with the entomopathogenic bacteria Xenorhabdus nematophila, it is also emerging as a model for mutualistic symbiosis [10]. It has also been suggested that an entomopathogenic Steinernematidae was the ancestor from which vertebrate-parasitic Strongyloidoids evolved [5], in the same way that Heterorhabditidae has been suggested to be the ancestor of vertebrate parasites of the Strongylomorphs group [5]. Therefore, nematodes from the Steinernema and Heterorhabditis genera can be useful as models to the mammal-parasitic nematodes. This evolutionary relationship can also help to understand host transitions in this and other clades of the nematode phylogeny.

Recent genomic studies in Steinernema carpocapsae have shown that specific evolutionary and functional signatures in its genome can be related to parasitism. These involve a set of expanded gene families likely involved in parasitism, orthologous genes shared with other parasitic nematodes not present in free-living species, ncRNA families reported to be enriched in parasites, and the expression of proteins putatively associated with parasitism and pathogenesis $[11,12]$. These signatures are most likely the result of evolutionary interaction with the hosts and suggest an active role during the pathogenic process.

It is known that hosts and pathogens interact in such a way that an equilibrium is never reached [13], with hosts evolving under selective pressure to avoid pathogen infection and pathogens with the pressure to evade host defenses [14]. Thus, changes in gene frequencies as a result of selection acting on one species create selection for changes in gene frequencies in the other species [15]. Two of the co-evolutionary models proposed are selective sweeps and dynamic polymorphisms, both involving reciprocal changes in host and pathogens. Selective sweeps occur when new alleles appear, by mutation or migration, eventually becoming fixed within the population by directional positive selection. This model is known as the "arms race". On the other hand, dynamic polymorphisms involve fluctuations in allele frequencies caused by selection and are inherently persistent, although fixation can occur as a result of genetic drift. This model is known as the "Red Queen" dynamics [15], or "trench warfare" [14], and genes in this model do evolve under balancing selection [14].

Well-known examples of a co-evolutionary "arms-race" dynamic are genes involved in immunity and defence $[13,14,16]$, i.e., genes directly involved in the hostpathogen interaction. However, it is not clear to what extent these interactions might alter the evolutionary patterns at the genome level, or to what extent they might affect levels of intraspecific diversity. One expectation would be that depending on the number of genes participating in the interaction, the total number of genes with specific signatures of selection, either from positive or balancing selection, would increase in pathogens, as compared with genomes of non-pathogenic organisms. Another prediction would be that the number of genes with signals of selection will increase in genes participating in the interaction as compared with genes that do not participate in it. It might be difficult to find all of the genes involved in the host-pathogen interaction, but a first approximation can be obtained by inducing the pathogen with host tissues and identifying the differentially expressed genes (e.g., [17]).

Comparative population genomics is showing that linked selection plays an important role in both the overall genetic diversity of a species and the variation in diversity within the genome [18]. If the host-pathogen interaction is increasing the number of genes evolving under positive selection that in turn are responsible for an increased number of selective sweeps, then a reduction in diversity is expected in the pathogen when compared with non-pathogen genomes. On the other hand, if the effects of the interaction are more related to balancing selection, then the above-mentioned reduction in diversity will not be found. Of course, a portion of the genes might be under positive selection and a portion of them under balancing selection, cancelling each other's effect on diversity. In any case, evolutionary genetic interactions might represent an additional determinant of genetic diversity.

Here we address some of these questions analysing the genome of the entomopathogenic nematode Steinernema carpocapsae (Nematoda clade IV). Through interspecific data, we look for ancient patterns of directional 
positive selection analysing nematodes of different lifestyles belonging to clade IV, and conducting a parallel analysis with nematodes belonging to clade $\mathrm{V}$ to give an independent assessment. At another level, using intraspecific data we look for more recent signatures of balancing or directional selection. To obtain clues regarding the impact of the parasitic lifestyle at genomic level, we compare our results with an analysis of a non-pathogenic nematode (Caenorhabditis briggsae). Also, we compare the patterns of selection in genes codifying differentially expressed proteins in S. carpocapsae after induction with insect tissues, with the patterns observed in genes for proteins that do not respond to this induction and with the more general patterns found in the massive scans.

\section{Results}

\section{Positive selection in interspecific data}

To assess differences in the impact of positive selection at a genomic level according to different lifestyles, we analysed two datasets, one from nematode clade IV and the other from clade V [3]. Each set included sequences from four nematodes. The dataset from clade IV, called C4N4, included the following species: the mycophagous Bursaphelenchus xylophilus, the free-living nematode Panagrellus redivivus, the entomopahtogenic Steinernema carpocapsae, and the vertebrate parasite Strongyloides ratti, and comprised 1552 orthologues. The dataset from clade V, C5N4, included the free-living nematodes Caenorhabditis briggsae and Pristionchus pacificus, the entomopathogenic Heterorhabditis bacteriophora, and the vertebrate parasite Haemonchus contortus, comprising 1510 orthologues. The number of genes analysed represents approximately $9.5 \%$ of the 16,333 genes estimated for S. carpocapsae [12] and $6.91 \%$ of the 21,850 genes estimated for C. briggsae (release WS244) [19].

Phylogenetic trees obtained from concatenated sequences for each dataset are shown in Fig. 1. Topologies are in agreement with previously published phylogenies $[3,12,20]$.

We conducted massive scans of positive selection analysing $\omega$ (omega), the nonsynonymous/synonymous substitution rate ratio $(\mathrm{dN} / \mathrm{dS})[21,22]$ (see Methods). We conducted several Likelihood-Ratio Tests (LRTs) for two of the existing codon models included in codeml, namely branch and branch-site models [23-26] (Table 1). For the branch model, we first compared the one-ratio model (model $=0$ ), which assumes a single $\omega$ for all lineages, against the free-ratio model that assumes an independent $\omega$ for each lineage (model $=1$ ). In the C4N4 set, $124(7.99 \%)$ of the tested genes had a different $\omega$ value among branches (LRT, d.f. $=4, p<0.05$ ). In C5N4, the number of genes showing different $\omega$ values among branches was 113 (7.48\%) (LRT, d.f. $=4, p<0.05)$. Different values of $\omega$ among branches are indicative of episodic evolution, contrary to the neutral expectation [21]. In the following analyses, for each dataset we conducted four different LRTs, testing the branches of three different species and the branch leading to parasites. Bursaphelenchus xylophilus (clade IV) and Pristionchus pacificus (clade V) are basal in the phylogenies and their branches were not analysed in order to reduce the number of tests performed. In addition, B. xylophilus has a more complex lifestyle [27], complicating its comparison with other nematodes.

We next tested the one-ratio model $($ model $=0$ ) against a several $\omega$ ratios model that estimates one $\omega$ as a free parameter for each of the specified branches and one
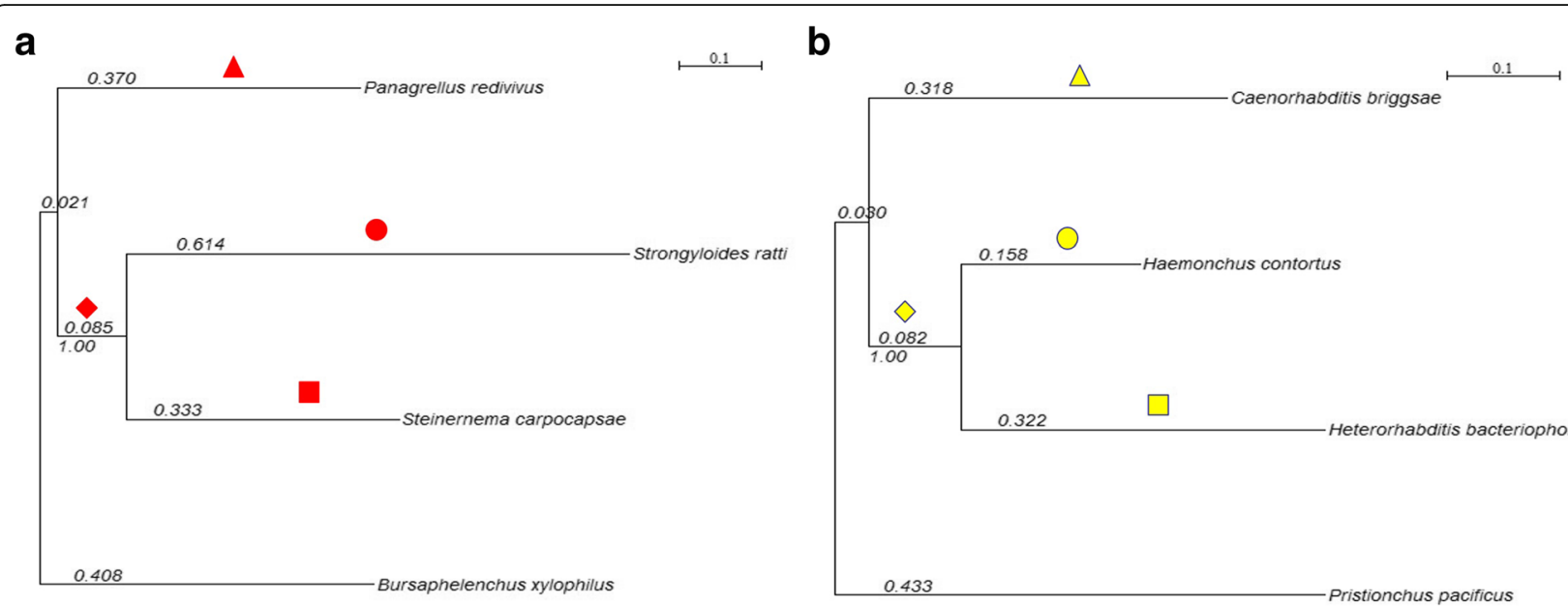

Fig. 1 Phylogenetic reconstructions for each clade obtained from concatenated sequences for each dataset. a phylogenetic reconstruction from the 1552 orthologues in clade IV; b phylogenetic reconstruction from 1510 orthologues in clade V. Branches used for Likelihood Ratio Tests (LRTs) are marked according to the species lifestyles; $\boldsymbol{\bullet}$, entomopathogenic; $\bullet$, vertebrate parasite; parasite branch; $\boldsymbol{\Lambda}$, free-living. All tests were based on an unrooted phylogeny; the trees are rooted for display purposes only. Values correspond to branch lengths, and bootstrap values are shown under the branch leading to the animal parasites 
Table 1 Interspecific analyses of positive selection

\begin{tabular}{|c|c|c|c|c|c|c|c|c|}
\hline \multirow{2}{*}{$\begin{array}{l}\text { Dataset name } \\
\text { Orthologues analysed (Global analysis) }\end{array}$} & \multicolumn{4}{|c|}{ C4N4 Clade IV } & \multicolumn{4}{|c|}{ C5N4 Clade V } \\
\hline & $\begin{array}{l}1552 \\
9.50 \%\end{array}$ & & & & $\begin{array}{l}1510 \\
6.91 \%^{\mathrm{a}}\end{array}$ & & & \\
\hline $\begin{array}{l}\text { Genes with } \omega \text { significantly different among branches } \\
(\mathrm{LRT}, p<0.05)\end{array}$ & $\begin{array}{l}124 \\
7.99 \%\end{array}$ & & & & $\begin{array}{l}113 \\
7.48 \%\end{array}$ & & & \\
\hline Foreground branch ( $\omega 1)$ & Sc & $\mathrm{Sr}$ & $(\mathrm{ScSr} r)$ & $\operatorname{Pr}$ & $\mathrm{Hb}$ & $\mathrm{HC}$ & $(\mathrm{HbHc})$ & $\mathrm{Cb}$ \\
\hline \multicolumn{9}{|l|}{ Branch model } \\
\hline $\begin{array}{l}\text { Genes with } \omega 1>1 \text { and significantly different than } \omega 0 \\
(\text { LRT, } p<0.05)\end{array}$ & $\begin{array}{l}9 \\
0.58 \%\end{array}$ & $\begin{array}{l}11 \\
0.71 \%\end{array}$ & $\begin{array}{l}2 \\
0.13 \%\end{array}$ & $\begin{array}{l}5 \\
0.32 \%\end{array}$ & $\begin{array}{l}17 \\
1.13 \%\end{array}$ & $\begin{array}{l}11 \\
0.73 \%\end{array}$ & $\begin{array}{l}7 \\
0.46 \%\end{array}$ & $\begin{array}{l}17 \\
1.13 \%\end{array}$ \\
\hline Genes with $\omega 1$ significantly greater than $1(\mathrm{LRT}, p<0.05)$ & 0 & 0 & 0 & 0 & 0 & 0 & 0 & 0 \\
\hline \multicolumn{9}{|l|}{ Branch-site model } \\
\hline $\begin{array}{l}\text { Genes with sites under positive selection }(\omega>1) \\
(\text { LRT, } p<0.05)\end{array}$ & $\begin{array}{l}74 \\
4.77 \%\end{array}$ & $\begin{array}{l}24 \\
1.55 \%\end{array}$ & $\begin{array}{l}21 \\
1.3 \% 5\end{array}$ & $\begin{array}{l}91 \\
5.86 \%\end{array}$ & $\begin{array}{l}61 \\
4.04 \%\end{array}$ & $\begin{array}{l}55 \\
3.64 \%\end{array}$ & $\begin{array}{l}20 \\
1.32 \%\end{array}$ & $\begin{array}{l}87 \\
5.76 \%\end{array}$ \\
\hline \multirow{2}{*}{$\begin{array}{l}\text { Average proportion of sites under positive selection per } \\
\text { gene (standard deviation) }\end{array}$} & $4.94 \%$ & $6.31 \%$ & $3.58 \%$ & $5.16 \%$ & $9.88 \%$ & $5.81 \%$ & $8.74 \%$ & $7.90 \%$ \\
\hline & $(0.053)$ & $(0.117)$ & $(0.045)$ & $(0.054)$ & $(0.140)$ & $(0.068)$ & $(0.155)$ & $(0.092)$ \\
\hline
\end{tabular}

Percentages are from the total of genes tested for each set, unless stated

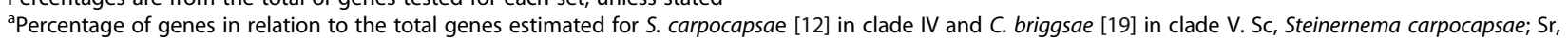
Strongyloides ratti; $\mathrm{Pr}$, Panagrellus redivivus; $\mathrm{Hb}$, Heterorhabditis bacteriophora; $\mathrm{Hc}$, Haemonchus contortus; Cb, Caenorhabditis briggsae

background $\omega$ for the remaining branches $($ model $=2)$. In total, we found 79 genes in which the selected branch had an estimated $\omega>1$ and a significant different value to the background $\omega$ (LRT, d.f. $=1, p<0.05$ ). From these, 27 $(1.73 \%)$ were from C4N4 and 52 (3.44\%) from C5N4. In the C4N4 set, the $S$. carpocapsae branch had 9 genes $(0.58 \%)$ with these characteristics. For the remaining tested branches, the percentage of genes ranged from 0.13 to $0.71 \%$ in $\mathrm{C} 4 \mathrm{~N} 4$ and $0.46-1.13 \%$ in C5N4 (Table 1). To test if $\omega$ was significantly greater than 1 in these cases, we contrasted a two-ratio model with $\omega$ fixed to 1 for the specified branch and a freely estimated $\omega$ for the remaining branches (model $=2-$ fix $\omega$ ), against a two-ratio model as described above (model $=2$ ). None of the genes tested had a $\omega$ significantly different from 1 (LRT, d.f. $=1, p>0.05$ ).

The branch models are conservative because positive selection often acts on one, or a few amino acids, and averaging $\omega$ over sites results in a lack of power [24, 25]. Therefore, we also used branch-site models, devised to detect positive selection affecting just a few sites along particular lineages $[24,25]$. We compared the branchsite model A (specified using model $=2$ and NSsites $=2$ ), against the same model with the difference that $\omega_{2}$ was fixed to 1 (model A1). Using a LRT we assessed if $\omega$ was significantly different from $\omega_{2}$ (i.e., different from 1 ). For the C4N4 set, we found $74(4.77 \%)$ genes with sites evolving under positive selection in the $S$. carpocapsae branch (LRT, d.f. $=1, p<0.05), 24(1.55 \%)$ in the Strongyloides ratti branch (LRT, d.f. $=1, p<0.05$ ), and 91 (5.86\%) in the Panagrellus redivivus branch (Table 1). In the branch leading to parasites ( $S$. carpocapsae and Strongyloides ratti), we found $21(1.35 \%)$ genes with sites under positive selection (LRT, d.f. $=1, p<0.05$ ). In the C5N4 set we found $61(4.04 \%)$ genes with sites under positive selection in the Heterorhabditis bacteriophora branch (LRT, d.f. $=1, p<0.05), 55(3.64 \%)$ in the Haemonchus contortus branch (LRT, d.f. $=1, p<0.05$ ), and 87 (5.76\%) in the Caenorhabditis briggsae branch (LRT, d.f. $=1, p<0.05)$ (Table 1). In the branch leading to parasites (Heterorhabditis bacteriophora and Haemonchus contortus), we found 20 (1.32\%) genes with sites evolving under positive selection (LRT, d.f. $=1, p<0.05$ ). As can be seen, vertebrate parasites showed some variation in the proportion of these genes between clades $(1.55 \%$ versus $3.64 \%)$ but not entomopathogenic (4.77\% versus $4.04 \%)$ or free-living (5.86\% versus $5.76 \%)$ nematodes (Table 1). However, when grouping species by the two main lifestyles, free-living and parasites, we found that parasitic nematodes showed lower proportions of genes with sites under positive selection $(214 / 6124=3.49 \%)$ than free-living nematodes $(178 / 3062=5.81 \%)$ (here the numbers in the denominators represent the total number of genes analysed for each lifestyle across clades). The difference between these proportion was highly significant $\left(\chi^{2}=26.87\right.$, d.f. $\left.=1, p<0.0000003\right)$.

Functional annotation of genes with sites under positive selection is shown in Additional files 1 and 2. In this analysis each gene is associated to one or more Gene Ontology (GO) terms. We found 26 significantly overrepresented (enriched) unique GO terms among the 210 protein-coding genes with signatures of positive selection (Additional file 3) in comparison to the remaining genes (Fisher's exact test; $p<0.05$ ). From these, 19 were enriched only in $S$. carpocapsae, one in Strongyloides ratti, five in $P$. redivivus, and only one was shared among the three species. In the 223 total protein-coding genes of clade $\mathrm{V}$, we found 28 significantly enriched unique GO terms (Additional file 4), six of which were 
private to Heterorhabditis bacteriophora, 18 were found only in Haemonchus contortus, and four were shared in both nematodes. No enriched term was found among the C. briggsae genes with signs of positive selection. Only one GO term was found to be enriched in both clades IV and V (GO:0005198, structural molecule activity); therefore, there were 53 unique enriched terms considering both clades. In general, in parasitic nematodes the total number of enriched terms (47) was strikingly high in relation to freeliving nematodes (6), even considering that the number of genes with signatures of positive selection was lower in parasitic nematodes (Additional files 3 and 4). Moreover, in parasitic nematodes, categories in cellular components, molecular function, and biological processes were represented, while in free-living nematodes, only categories related to molecular function were observed (Fig. 2). Most of the enriched terms in S. carpocapsae are related to the immune response or antimicrobial peptide production (Additional file 5). One example is the $S$. carpocapsae gene snf12 (g2184.t1), encoding for the transmembrane protein SNF-12 (Uniprot O45813), a sodium-dependent neurotransmitter symporter, member of the solute carrier 6 family (SLC6), reported to be essential for two immune signalling pathways (neuroendocrine TGF-b pathway and a p38 MAPK pathway) in C. elegans [28]. The enrichment analyses showed only one term related to mitochondrial function found in S. carpocapsae; however, in the parasite $H$. contortus an important number of terms related to mitochondria were observed (Fig. 2, Additional files 3 and 4).

\section{Signatures of selection in intraspecific data}

To conduct this analysis at genome level, we sequenced the genomes of four additional S. carpocapsae strains. To further assess the impact that different lifestyles could have in the selection patterns across the genome, we did the same analysis on previously published data from five strains of C. briggsae isolated from around the world [29]. A description of the strains used is provided in the Methods section.

We conducted tests of neutrality with the Tajima's D statistic in sliding windows of $1000 \mathrm{bp}$ across the genome, including both genic and intergenic regions. Significant positive values of Tajima's $D$ are indicative of balancing selection or could be caused by demographic processes that increase genetic variation [30, 31], whereas significant negative values are indicative of directional selection or could be caused by demographic processes reducing genetic variation, such as a recent bottleneck [30-32]. Directional selection can be due to either positive or negative selection [13]. To account for demographic effects, we used the observed distribution of the data to correct the Tajima's D confidence limits to identify windows with significant values (see Methods).

From the $S$. carpocapsae assembled genome, we analysed 84,767 windows, from which 69,694 had enough coverage to conduct the analysis (Table 2). From these, 400 windows $(0.47 \%)$ were invariable (in these windows the estimation of Tajima's D is not possible). The remaining 69,294 windows, which included 14,994 protein-coding genes (representing $91.84 \%$ of the protein-coding genome), were used to build the observed distribution of Tajima's D values. These values ranged from -2.105 to 2.592 . The corrected confidence limits for $S$. carpocapsae were -0.468 for negative and 2.264 for positive values, which differed from the uncorrected limits obtained with the Tajima's beta distribution (-1.733 and 1.975) (Fig. 3). Using the corrected limits, we found 2,759 windows with significant $\mathrm{D}$ values, which included 530 genes (3.53\% of the genes analysed). From these, 1,375 windows presented significant positive values, comprising 228 protein-coding genes $(1.52 \%$ of the genes analysed) (Additional file 6). The S. carpocapsae gene (g6196t.1) with the most positive D value is orthologous to

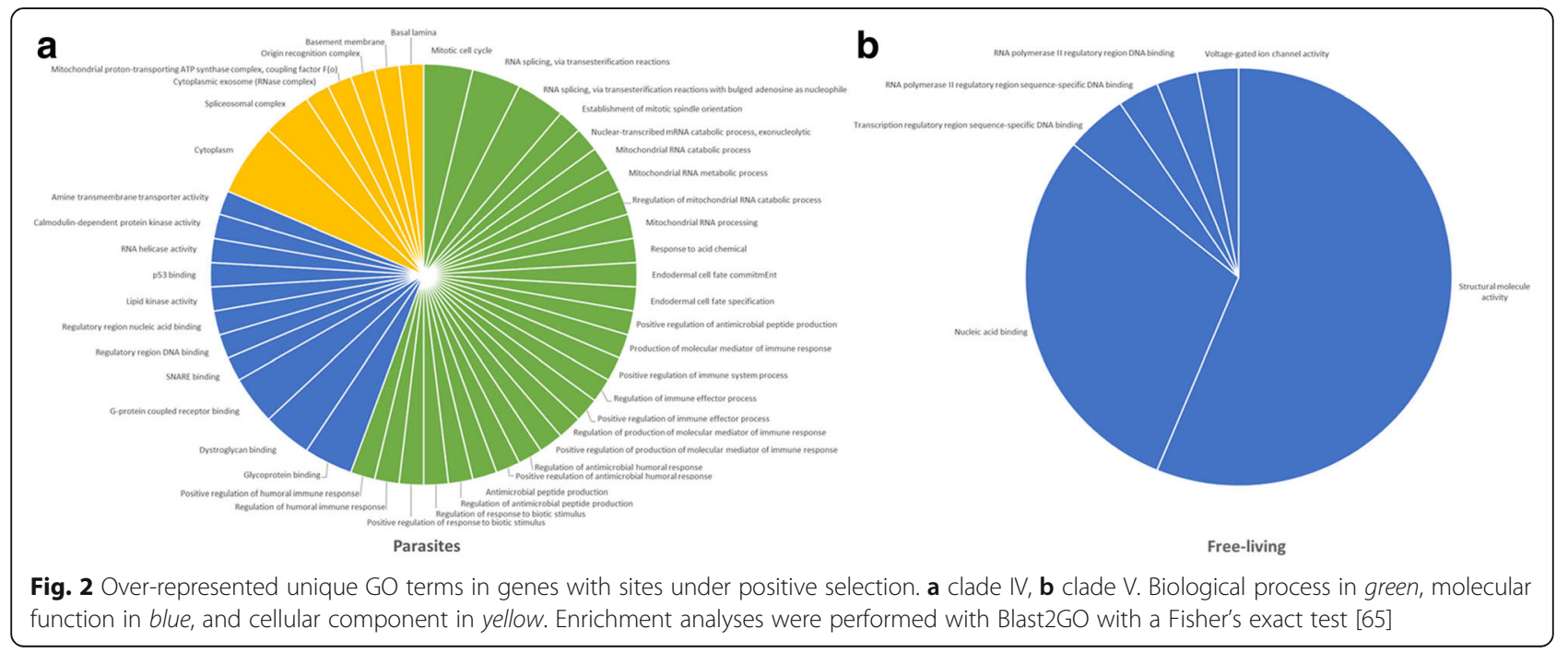


Table $\mathbf{2}$ Intraspecific analyses of selection

\begin{tabular}{|c|c|c|}
\hline Species & S. carpocapsae & C. briggsae \\
\hline Number of windows & 84,767 & 108,421 \\
\hline Windows with coverage $>90 \%$ & 69,694 & 65,933 \\
\hline Invariable windows & 400 & 21 \\
\hline Windows with Tajima's D values & 69,294 & 65,912 \\
\hline $\begin{array}{l}\text { Genes covered ( }>50 \%) \text { in windows with D values } \\
\text { (Global number of genes analysed) }\end{array}$ & 14,994 & 15,473 \\
\hline Tajima's D range of values & $-2.105-2.592$ & $-2.057-2.452$ \\
\hline Tajima's D average & 1.097 & 0.355 \\
\hline Confidence limits according to theoretical distribution [30] & $-1.733-1.975$ & $-1.733-1.975$ \\
\hline Theoretical significant windows & $\begin{array}{l}6522 \\
(6500 \text { positive, } 22 \text { negative) }\end{array}$ & $\begin{array}{l}80 \\
\text { (74 positive, } 6 \text { negative) }\end{array}$ \\
\hline Confidence limits obtained from the observed distribution & $-0.468-2.264$ & $-0.355-1.369$ \\
\hline Significant windows according to the observed distribution ${ }^{a}$ & $\begin{array}{l}2,759 \\
\text { (1,375 positive, } 1,384 \text { negative) }\end{array}$ & $\begin{array}{l}2,624 \\
(1,313 \text { positive, } 1,311 \text { negative })\end{array}$ \\
\hline Genes in windows with significant D values ${ }^{a}$ & $530(3.53 \%)$ & $487(3.15 \%)$ \\
\hline - Significant positive & $228(1.52 \%)$ & $247(1.6 \%)$ \\
\hline - Significant negative & $302(2.01 \%)$ & $240(1.55 \%)$ \\
\hline$\pi$ values range & $0.00035-0.075$ & $0.00035-0.045$ \\
\hline Average $\pi$ value & 0.006700 & 0.007763 \\
\hline values range & $0.35349-61.5065$ & $0.3535-49.1345$ \\
\hline Average $\Theta$ value & 5.369212 & 7.166656 \\
\hline
\end{tabular}

${ }^{a}$ Windows falling in the upper (positive) and lower (negative) $2 \%$ of the observed distribution

the C. elegans nuo-6 gene, coding for a subunit of the mitochondrial NADH dehydrogenase (ubiquinone) complex (complex I) (Uniprot Q23098). Meanwhile, 1,384 windows presented significant negative values, comprising 302 protein-coding genes (2.01\%) (Additional file 6). The gene with the most negative D value corresponded to a $S$. carpocapsae gene (g10336.t1) that is orthologous to the C. elegans gen sut-1, coding for a protein involved in embryo development (Uniprot H2KYJ0). Additional file 6 contains brief descriptions of all the genes with significant $\mathrm{D}$ values. The number of windows with significant values according to the theoretical distribution are shown in Table 2 for comparison.

For C. briggsae we analysed 108,421 windows, from which 65,933 had enough coverage to conduct the analysis (Table 2). From these, 21 windows $(0.02 \%)$ were invariable. The remaining 65,912 windows, which included 15,473 protein-coding genes (representing $66.52 \%$ of the protein-coding genome) were used to build the observed distribution of Tajima's D values. D values ranged from -2.057 to 2.452 for this distribution. In C. briggsae, the confidence limits from the observed data distribution (-0.355 and 1.369) also differed from the confidence limits for the theoretical beta distribution $(-1.733$ and 1.975) (Fig. 3). We found 1,313 windows with significant positive values, comprising 247 protein-coding genes (1.6\% of the genes analysed). The significant negative values included 1,311 windows comprising 240 protein coding genes $(1.55 \%)$ (Table 2). The total number of genes with significant D values was 487 (3.15\% of the genes analysed). The comparison with results using the theoretical distribution are shown in Table 2.

The mean of Tajima's D values in S. carpocapsae was bigger (1.097) and significantly different from the average in C. briggsae (0.355) (W=3759800000, $\left.p<2.2 \times 10^{-16}\right)$. The difference in the average values might be caused by natural selection or by demographic processes. However, this difference was not due to a simple displacement of the distribution of one species in relation to the other, but to a clear change in the shape of the distribution. In fact, the distribution of Tajima's D values were significantly different between these species (K-S test, $\mathrm{D}=0.54736 p<2.2 \times 10^{-16}$ ), with the distribution of $S$. carpocapsae more skewed to positive values (Fig. 3).

Other statistically significant differences between $S$. carpocapsae and C. briggsae included the proportion of invariable windows $\left(\chi^{2}=321.74\right.$, d.f. $\left.=1, p<6.1 \times 10^{-72}\right)$, and the theta average $(\mathrm{t}=-82.681$, d.f. $=134130, p<$ $2.2 \times 10^{-16}$ ) (Table 2). 


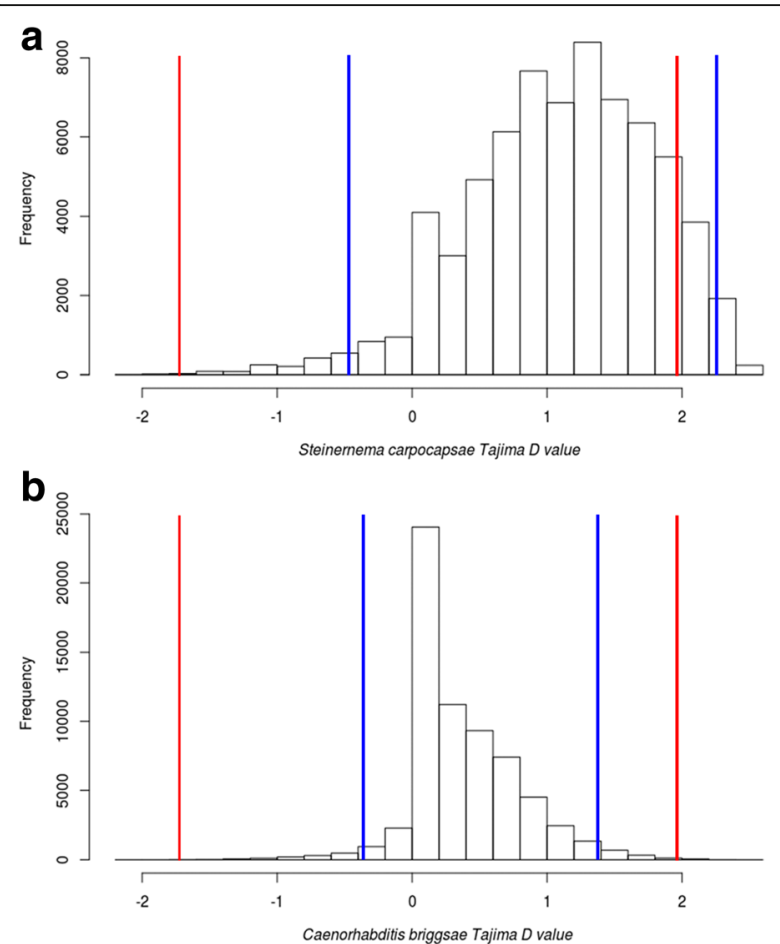

Fig. 3 Distribution of Tajima's D values estimated in sliding windows of 1,000 bp across the genomes. a Steinernema carpocapsae; b Caenorhabditis briggsae. D values were non-continuous (i.e., were distributed in discrete intervals). Red lines correspond to the maximum and minimum confidence limits according to [30]. Blue lines correspond to the maximum and minimum corrected confidence limits from the observed distribution (upper and lower 2\%)

Functional annotations of genes in windows with significant Tajima's D values are shown in Additional files 7 and 8 . In S. carpocapsae, there were no enriched GO terms in the genes with significant values, either positives or negatives.

\section{Selection in differentially expressed proteins}

To assess how selection is affecting genes related to the host-pathogen interaction, we analysed patterns of selection in genes for differentially expressed proteins. In a previous study, nematodes in the Infective Juvenile (IJ) stage were induced with host insect (Galleria mellonella) tissues to detect differentially expressed proteins [12]. In that study, we conducted a qualitative analysis with which we identified 1,154 differentially expressed proteins. In the present study, using the same data, we conducted a label-free quantitative analysis (see Methods). We identified 147 significantly differentially expressed proteins in relation to the control. Considering both qualitative and quantitative analyses, there were 1301 differentially expressed proteins (Additional file 9). In addition, we detected 2,237 proteins that were not differentially expressed between samples and the control (Additional file 10).

We then compared the results of the differential expression analysis with the results obtained from the analyses of selection with both interspecific and intraspecific data to assess if the patterns of selection in the differentially expressed genes were different in relation to the patterns in non-differentially expressed genes, and in relation to the global scans. We obtained data for 590 genes of the identified proteins in our interspecific scan for positive selection using the branch-site tests, including 143 differentially expressed and 447 non-differentially expressed genes. From these, we found $7.69 \%$ (11/143) differentially expressed genes with sites under positive selection, a higher percentage than the $6.71 \%(30 / 447)$ found in genes that were not differentially expressed (Table 3 ) (Additional file 11), although the difference was not statistically significant (Fisher's exact test, $p=0.706381$ ). Also, differentially expressed genes had a higher proportion of genes under selection $(7.69 \%)$ in relation to the $4.77 \%$ in the global analysis (74/1552) (Table 1), but again the difference was not statistically significant (Fisher's exact test, $p=0.15624$ ).

In the intraspecific analysis, we obtained data for 3093 genes of the identified proteins (1009 differential and 2084 non-differential). Among the differentially expressed proteins, $4.16 \%$ (42/1009) presented significant Tajima's D values in their coding genes. From these, 2.28\% (23/1009) presented positive D values, and $1.88 \%$ (19/1009) presented negative $\mathrm{D}$ values. In non-differentially expressed proteins, we found 3.8\% (79/2084) significant D values, $1.4 \%(29 / 2084)$ with positive values, and $2.4 \%(50 / 2084)$ with negative values (Table 3) (Additional file 11). Differentially expressed genes showed a slightly higher proportion of genes with significant D values $(4.16 \%)$ in relation to the $3.53 \%(530 / 14994)$ in the global scan (Table 2) and the non-differentially expressed genes (3.8\%), although the differences were not significant (Fisher's exact test, $p=0.292928$ and $p=0.621698$, respectively).

Table 3 Patterns of selection in the genome of Steinernema carpocapsae and in identified expressed proteins

\begin{tabular}{lllll}
\hline Interspecific analysis & $N$ & & Positive selection $^{\text {a }}$ \\
\hline Differentially expressed & 143 & & $11(7.69 \%)$ & \\
$\begin{array}{l}\text { Non-differentially } \\
\text { expressed }\end{array}$ & 447 & & $30(6.71 \%)$ & \\
$\begin{array}{l}\text { Intraspecific analysis } \\
\text { Nifferentially expressed }\end{array}$ & N & Significant D & Significant & Significant \\
positive Dc & negative Dc \\
$\begin{array}{l}\text { Non-differentially } \\
\text { expressed }\end{array}$ & 2084 & $79(4.16 \%)$ & $23(2.28 \%)$ & $19(1.88 \%)$ \\
\end{tabular}

expressed

$N$ number of genes analysed

${ }^{a}$ Branch-sites test, LRT, $p<0.05$

'Tajima's D, 96\% confidence level obtained from the real distribution

'Tajima's D, 98\% confidence level obtained from the real distribution 
Differentially expressed genes with significant positive D values $(2.28 \%)$ showed also an increased proportion in relation to the $1.52 \%(228 / 14994)$ in the global scan (Table 2) and the non-differentially expressed genes (1.4\%). Although the $p$-values were marginal (Fisher's exact test, $p=0.066236$ and $p=0.075006$, respectively), these differences were not significant.

\section{Discussion}

This study is a first assessment of the impact that parasitic lifestyle might have on nematode genomes. We characterized selection patterns at the genome level in parasitic and free-living nematodes from two clades of the Nematoda phylogeny to assess consistency. In addition, we assessed whether genes responding to the interaction with host tissues showed specific patterns of selection, using the entomopathogenic nematode $S$. carpocapsae as a model.

In the interspecific analysis, the observed proportions of genes with positively selected sites found in parasites as a whole and in free-living nematodes were similar in both clades (Table 1), despite differences in vertebrate parasites. Although we detected a significantly higher proportion of genes with sites under positive selection in free-living nematodes, functional enrichment tests showed a higher number of enriched GO terms and a different enrichment profile in parasites (Additional file 3: Figure S2), indicating that the difference is rather qualitative. This gives further support to previous observations indicating that an arms-race interaction between hosts and pathogens affects specific genetic functions, but does not necessarily increase the global number of positively selected genes [12]. In parasites, most of the enriched functions involved immune response, production of antimicrobial compounds, and mitochondrial processes (Fig. 2, Additional files 3 and 4). It is known that symbiotic entomopathogenic bacteria produce antimicrobial peptides during infection to eliminate other potential microbial pathogens from the host [33]. Nematodes could be contributing to this end with their own antimicrobial arsenal. In addition, immune response might be needed to fight against attacks from these same microbes or even to defend themselves from their exponentially growing symbiont, also during the infection process. In C. elegans, snf-12, homologous to one of the genes we identified in S. carpocapsae, has a role in defence against bacterial and fungi pathogens [28]). As there are no known symbionts in C. elegans, both possibilities, defence against other pathogens and against the symbiont remain open in EPNs. Enrichment in mitochondrial processes is interesting because there are few examples in which genes related to mitochondrial processes might be linked to parasitism [12]. Genes relevant to the mitochondrial function were also identified here in the intraspecific analysis. One of them, nuo-6, has been used for phylogenetic analysis in Taenia spp. and other species [34], although so far we did not find reports indicating any role in pathogenesis. The other gene, sut-1, is involved in development [35], as is ATAD-3, a protein previously identified as potentially relevant in the pathogenic process [12]. This could suggests that developmental processes are relevant in pathogenesis, a reasonable expectation considering that during the initial steps of infection nematodes need to recover from the resistance larval stage (IJ) to the more active parasitic stage [36]. The evaluation of different alleles or mutations in these genes to observe whether there are differential phenotypes in the pathogenic process could be a promising future area of research.

Interestingly, in both clades, the branches leading to parasitic nematodes (S. carpocapsae and Strongyloides ratti in clade IV and Heterorhabditis bacteriophora and Haemonchus contortus in clade V) had lower proportions of genes with sites evolving under positive selection than the branches of each of the parasitic species. This is difficult to interpret, however the increase in this proportion in each of the species might be related to host-shifting and specialization, mediated by coevolutionary dynamics.

In our interspecific analyses we scanned relatively low numbers of genes (between 7 and $9 \%$ of the proteincoding genomes) because nematode species are in general highly divergent [37], making it difficult to find a high number of one-to-one orthologues. Also, the genes analysed can be considered to be among the most conserved, and it can be counterintuitive to look for positive selection in these genes. However, these genes are especially interesting because they show variation at the sequence level while preserving their function, making them more relevant to assessing whether the observed differences between the species were fixed by positive selection or by random drift [38, 39]. In our case, all but one of the analysed orthologues showed variation among the species at the amino acid level but only a small proportion of them $(1.3-5.76 \%)$ showed signs of positive selection. This leaves open the possibility that most of the observed amino acid variation is neutral, or is due to linked selection, possibilities that need to be investigated further. In other studies, the proportion of genes under positive selection varied between $2.4 \%$ in mammals [16] to $43 \%$ in ants [40], also indicating that substantial amounts of variation are not explained by positive selection.

To conduct a more comprehensive analysis of the effect that lifestyle might have at genomic level, including coding and intergenic regions, an intraspecific analysis is appropriate. With this analysis, more recent or ongoing selection events can be detected [13]. Demographic processes might also produce signals that can be confounded with signatures of selection, reflected in positive $D$ values (for processes increasing diversity) or in 
negative $\mathrm{D}$ values (for processes decreasing diversity) $[13,30,32]$. However, demographic events are expected to affect all genes in a genome, whereas selection pressures act in specific loci of the genome [30, 32, 41]. Thus, a method to discern demographic from selective effects is to conduct a genome-wide analysis. Better results can be achieved if specific population parameters can be modelled for the specific populations under analysis [42], although this requires a good characterization of the variation in the populations that is currently lacking for nematode species. Our strategy allowed us to obtain an observed distribution from which we estimated corrected confidence limits to detect Tajima's D values that were significantly different from both the expected values under neutrality and the values linked to demographic processes, which were assumed to be reflected in the average of $\mathrm{D}$ values across all the analysed windows. The comparison of these confidence limits with those obtained from the theoretical distribution proposed by Tajima [30] indicated that our approach avoided a bias in accepting or rejecting candidate regions. The Tajima confidence limits are asymmetrical in relation to the real data distribution (Fig. 3). Thus, the estimation of confidence limits from the real distribution of $\mathrm{D}$ values improves the power of the test and avoids bias towards positive or negative values. A similar result was obtained by Schmidt and Pool [43] using simulations. One problem of our approach is that when performing comparisons between species, the percentage of significant positive and negative values will always be similar, because the idea is to accept a predefined marginal percentage of values from each side of the distribution (in our case, 2\%). This nullifies any possible conclusion regarding the impact of lifestyle in the proportion of genes with signatures of selection. Nevertheless, the comparison of the distribution itself can gives us some clues regarding the impact of lifestyle in the patterns of selection at the genomic level. The shape of the distribution of $S$. carpocapsae is different and more skewed to positive values of Tajima's D in relation to the distribution of C. briggsae (Fig. 3). This might be indicative of pervasive balancing selection acting in the genome of the entomopathogenic nematode, due to Red Queen or trench warfare coevolutionary host-pathogen dynamics. An alternative explanation is that demographic processes are not only affecting the average $\mathrm{D}$ value, but also changing the shape of the distribution, a more complex scenario that needs to be further investigated; perhaps by modelling different demographic scenarios to assess specific effects in Tajima's $\mathrm{D}$ distribution. Another problem in our comparison is that there is more genetic distance among the C. briggsae strains than among $S$. carpocapsae strains included in the analyses (Additional file 12). This is reflected in the significantly higher number of invariable windows detected in $S$. carpocasae in relation to C. briggsae. However, positive values of Tajima's D correlate with higher levels of nucleotide diversity in relation to segregating sites [30]. Therefore, the fact that $S$. carpocapsae shows more windows with positive $\mathrm{D}$ values than $C$. briggsae, when there is less genetic distance among their strains, reinforces the idea that balancing selection is acting with more strength in $S$. carpocapsae due to its pathogenic lifestyle. Under balancing selection, more alleles will be maintained in each segregating site. S. carpocapsae has a significant lower theta $(\theta)$ average than $C$. briggsae (Table 2), an estimator that is proportional to the number of segregating sites [30]. To maintain different alleles in a significant number of these sites, a higher strength of selection is required.

To assess if genes participating in the interaction with the host show different patterns of selection, we compared the proportion of genes with signatures of selection in differentially expressed genes against the proportion found in the global analyses and with the proportion of nondifferentially expressed genes (Table 3 ). In the interspecific analysis, the proportion of genes with positive selected sites was higher in differentially expressed genes (7.69\%) in relation to both, the global analysis (4.77\%) and the non-differentially expressed genes (6.71\%), although the differences were not statistically significant. Interspecific analyses are suitable for detecting past selection [13] in a time frame commensurate with the divergence time of the species analysed. In our analysis, we detected ancient selection and it is possible that the genes that were targeted at that time are different than the genes that are currently relevant in the interaction. In the intraspecific analyses, we observed a slightly higher proportion of genes with significant $\mathrm{D}$ values among the differentially expressed genes $(4.16 \%)$ in relation to both the global scan $(3.53 \%)$ and to the non-differentially expressed genes $(3.80 \%)$ that were not significant. Interestingly, the differences were more evident in the proportion of genes with significant positive $\mathrm{D}$ values. There were $2.28 \%$ of these genes among the differentially expressed genes, $1.52 \%$ in the global scan, and $1.40 \%$ in the non-differentially expressed genes. It is also interesting that the tendency is reverted in the proportion of genes with significant negative $\mathrm{D}$ values, which is lower in differentially expressed genes $(1.88 \%)$ than in the global scan $(2.01 \%)$ or in the non-differentially expressed genes $(2.4 \%)$.

The lack of significance in the observed differences precludes further conclusions. In the case of the interspecific analysis, a clearer picture might emerge by analysing more closely related species. Also, both analysis were based on protein-coding expressed genes detected under specific conditions and methods. Testing for different conditions, aiming to capture different stages during the pathogenic process or specific groups of genes, might increase the power of the tests and help to 
tease apart the relevance of specific types of selection along the process.

\section{Conclusions}

Our study provides a first portrait of the effects that lifestyle might have in shaping the patterns of selection at the genomic level. Our massive scan for positive selection indicates that in pathogenic nematodes, positive selection is targeting specific genetic functions, possibly due to an arms-race host-pathogen interaction. Our intraspecific genomic analysis indicates that balancing selection could be acting with more strength in the $S$. carpocapsae genome in comparison with the genome of free-living $C$. briggsae, leaving open the possibility that this increased effect of balancing selection is due to Red Queen or trench warfare co-evolutionary host-pathogen dynamics. Until now, the examples of genes showing signatures of either of these evolutionary genetic interactions were limited to single genes, mostly related to effectors or genes related to the immune response. Here we found examples in which more conserved genes and genes related to mitochondrial function could also be the target of selection due to hostpathogen dynamics, opening new avenues of research. Finally, differentially expressed genes responding to host tissues, are slightly enriched in balancing selection, in agreement with the idea that this type of selection might be more relevant to genes participating in the hostpathogen interaction than other types of selection.

\section{Methods}

\section{Interspecific analysis}

Nucleic and amino acid sequences of eight nematode species belonging to clades IV and V [3], with parasitic and free-living lifestyles were analysed. Sequences from seven of these nematodes were downloaded from Wormbase [19] (release WS244). Sequences from Steinernema carpocapsae strain Breton were generated previously by our group [12] (GenBank Bioproject ID\# 39853). Nematodes from clade IV included Panagrellus redivivus (free-living), Strongyloides ratti (vertebrate parasite), Steinernema carpocapsae (entomopathogenic), and Bursaphelenchus xylophilus (mycophagous) that causes the pine wilt disease [27]. Nematodes from clade V included Caenorhabditis briggsae and Panagrellus redivivus (free-living), Heterorhabditis bacteriophora (entomopathogenic), and Haemonchus contortus (vertebrate parasite).

Massive scans of positive selection were conducted in each clade, as previously described [12]. In brief, one-toone orthologue gene sets were identified with OrthoMCL v. 2.0.7 [44]. Amino acid sequences were aligned with Clustalw2 v. $2.1[45,46]$ and concatenated. Phylogenetically informative blocks were recovered with Gblocks [47]. The best-fit evolutionary model was estimated with ProtTest [48]. Consensus phylogenetic trees were reconstructed with PhyML v. 3.0 [49]. For the analyses of positive selection, complete nucleotide sequences from each gene were aligned with RevTrans v. 1.4 [50], preserving codon homology. Signatures of positive selection were identified with Codeml from the PAML package v. 4.6 [26]. Codeml calculates $\omega$, the ratio of nonsynonymous mutations per nonsynonymous site to the number of synonymous mutations per nonsynonymous site $(\omega=\mathrm{dN} / \mathrm{dS})$ $[21,22]$. Where $\omega>1$ is indicative of positive selection, $\omega$ $=1$ corresponds to the neutral expectation and $\omega<1$ indicates negative or purifying selection. Two models, branch and branch-site, were used to identify genes and sites

Table 4 Likelihood Ratio Tests (LRTs) performed for each selected branch

\begin{tabular}{|c|c|c|c|}
\hline $\begin{array}{l}\text { Codon substitution } \\
\text { model }\end{array}$ & LRT & Models & Parameters \\
\hline Branch & $\begin{array}{l}H_{0} \text { : Same } \omega \text { for all branches } \\
H_{1} \text { : Different } \omega \text { for all branches }\end{array}$ & $\begin{array}{l}\text { Model 0: one-ratio model vs Model 1: } \\
\text { free-ratios model. }\end{array}$ & $\begin{array}{l}\text { Model } 0: \text { model }=0, \text { fix_omega }=0, \\
\text { omega }=0 \\
\text { Model } 1: \text { model }=1, \text { fix_omega }=0, \\
\text { omega }=0\end{array}$ \\
\hline Branch & $\begin{array}{l}H_{0} \text { : Same } \omega \text { for all branches } \\
H_{1} \text { : A different } \omega \text { for the foreground } \\
\text { branch }\end{array}$ & $\begin{array}{l}\text { Model 0: one-ratio model vs Model 2: } \\
\text { different ratio in the specified branch }\end{array}$ & $\begin{array}{l}\text { Model } 0: \text { model }=0 \text {, fix_omega }=0 \text {, } \\
\text { omega }=0 \\
\text { Model } 2 \text { : } \text { model }=2 \text {, fix_omega }=0, \\
\text { omega }=0\end{array}$ \\
\hline Branch & $\begin{array}{l}H_{0}: \omega=1 \text { for the foreground branch } \\
H_{1}: \omega \neq 1 \text { for the foreground branch }\end{array}$ & $\begin{array}{l}\text { Model 2: different ratio in specified branch } \\
\text { vs Model } 2 \text { fix } \omega \text { : ratio }=1 \text { in the specified } \\
\text { branch }\end{array}$ & $\begin{array}{l}\text { Model 2: } \text { model = 2, fix_omega }=0 \text {, } \\
\text { omega }=0 \\
\text { Model } 2 \text { fix } \omega \text { : } \text { model }=2 \text {, fix_omega }=1 \text {, } \\
\text { omega }=1\end{array}$ \\
\hline Branch-Site & $\begin{array}{l}\mathrm{H}_{0} \text { : Same } \omega \text { for all sites among } \\
\text { branches. } \\
\mathrm{H}_{1} \text { : Different } \omega \text { for all sites in the } \\
\text { foreground branch. }\end{array}$ & $\begin{array}{l}\text { A: different ratio per site in specified } \\
\text { branch vs } A 1 \text { : } \\
\omega \text { ratio }=1 \text { per site in the specified branch }\end{array}$ & $\begin{array}{l}\text { A: } \text { model }=2, \text { NSsites }=2, \text { fix_omega }=0 \\
\text { A1: } \text { model }=2, \text { NSsites }=2, \text { fix_omega }= \\
1, \text { omega }=1\end{array}$ \\
\hline
\end{tabular}

NSsites $=0$ for all the branch models. kappa was estimated for each gene and fixed with fix_kappa $=1$ and kappa = estimated value. For all the models these parameters were the same: noisy $=3$, verbose $=0$,runmode $=0$, seqtype $=1$, CodonFreq $=2$, clock $=0$, aaDist $=0$, icode $=0$, fix_alpha $=1$, alpha $=0$, Malpha $=0$, $\mathrm{ncat} \mathrm{G}=10$, getSE $=0$, RateAncestor $=0$, Small_Diff $=.5 \mathrm{e}-6$, cleandata $=1$, method $=1$ 
under directional positive selection, using Likelihood Ratio Tests (LRTs) to assess significance. We used a script that helped with the automatization of Codeml. LRTs parameters used for each model are shown in Table 4. Significance of differences in the proportion of genes with sites under positive selection between parasitic and free-living nematodes was assessed with a $\chi^{2}$ test in a $2 \times 2$ table.

\section{Intraspecific analysis}

Total DNA from four different strains of $S$. carpocapsae was extracted from a pool of nematodes using phenol/ chloroform extraction protocol described in [51]. DNA yield and integrity was measured with a 2100 Bioanalyzer (Agilent) using an Expert High Sensitivity DNA chip and sequenced with the Illumina HiSeq 2500 platform, at Cinvestav-Langebio Core Facilities. Details of each strain are shown in Table 5. Reads were aligned to the reference sequence [12] (GenBank Bioproject ID\# 39853) with the Burrows-Wheeler Aligner (BWA) v.0.7.12 MEM algorithm [52, 53].

We selected Caenorhabditis briggsae as a model of free-living nematode for comparison because it was the only free-living species with several available genomes from different strains. Sequences from $C$. briggsae were downloaded from the NCBI Sequence Read Archive (SRA; http://www.ncbi.nlm.nih.gov/sra) and aligned with BWA-MEM to the reference genome assembly PRJNA10731 (release WS253) of C. briggsae strain AF16 [54], downloaded from Wormbase [19]. Accession numbers of all the strains are shown in Table 5.

SNP calling was completed with a Samtools v.1.3.1 and Bcftools v. 1.2 [55-57] pipeline. The output files, in the Variant Call Format (VCF), were used to construct haplotype map-like files [58], for each of the nematode species. These resulted from the alignment of the VCF files to the reference genomes used for the alignments. Regions with repetitive elements or with a lack of coverage were filtered.

The program Massive Tajima developed in our group (available upon request), was used to estimate the index of nucleotide diversity $(\pi)$ [59], the proportional estimator of segregating sites theta $(\theta)$ [60], and Tajima's D [30] in non-overlapping sliding windows. This program is capable of generating and analysing the observed distribution of $\mathrm{D}$ values. The analysis was performed across the complete genomes in windows of $1,000 \mathrm{bp}$. In windows without variation $(\pi=0)$ the estimation of Tajima's $\mathrm{D}$ is not possible. Windows with less than $90 \%$ of sequence coverage for one or more species were discarded. We obtained the average and the observed distribution of $\mathrm{D}$ values for each species. Invariable windows were excluded from the distribution. This statistic is sensitive to demographic processes that might produce signals that can be confounded with signatures of selection [13]. To ameliorate the negative demographic effects (see Discussion), we used the observed distribution to calculate corrected confidence limits with the method that Schmidt and Pool used to correct the confidence limits in simulated distributions [43]. A determined percentile on each tail of the distribution is used to find the confidence limits to identify windows with significant D values. To achieve a confidence of $95 \%$, we intended to record the 2.5 percentile on each tail of the observed distribution. However, the D values were non-continuous (i.e., were distributed in discrete intervals, see Fig. 3), forcing us to select the 2 percentile on each tail (or jump to

Table 5 Steinernema carpocapsae and Caenorhabditis briggsae strains used for intraspecific analysis

\begin{tabular}{|c|c|c|c|c|c|}
\hline Species & Strain & Geographic origin & Sequencing platform & Source & Reference \\
\hline S. carpocapsae & Breton $^{a}$ & France & $454 f l x$, SOLiD & NS & {$[12]$} \\
\hline S. carpocapsae & All/USA strain & USA & HiSeq 2500 & $H G B$ & This study \\
\hline S. carpocapsae & Az20 & Açores, Portugal & HiSeq 2500 & NS & This study \\
\hline S. carpocapsae & Az154 & Açores, Portugal & HiSeq 2500 & NS & This study \\
\hline S. carpocapsae & Az157 & Açores, Portugal & HiSeq 2500 & NS & This study \\
\hline C. briggsae & $\mathrm{AF} 16^{\mathrm{a}}$ & Guajarat, India & Combined & Wormbase & [49] \\
\hline C. briggsae & JU1348 & Kerala, India & HiSeq 2000 & $\begin{array}{l}\text { NCBI } \\
\text { SRR1793004 }\end{array}$ & [29] \\
\hline C. briggsae & QR25 & Quebec, Canada & GA $\| x$ & $\begin{array}{l}\text { NCBI } \\
\text { SRR1793006 }\end{array}$ & [29] \\
\hline C. briggsae & VX0034 & Hubei, China & HiSeq 2000 & $\begin{array}{l}\text { NCBI } \\
\text { SRR1793007 }\end{array}$ & [29] \\
\hline C. briggsae & ED3101 & Nairobi, Kenya & GA $\| x$ & $\begin{array}{l}\text { NCBI } \\
\text { SRR1793002 }\end{array}$ & [29] \\
\hline
\end{tabular}

Strains are natural isolates. Sequencing platform are: Combined, whole-genome shotgun sequencing (WGS) with a high-resolution, sequence-ready physical map; GA, Genome Analyzer. Libraries were Paired End (100bpx2). Strains sources are: NS, Nelson Simões; HGB, Heidi Goodrich-Blair. NCBI, National Centre for Biotechnology Information

${ }^{a}$ Reference genome; S. carpocapsae from [12], and C. briggsae from wormbase.org (c_briggsae. PRJNA10731.WS253) [19] 
the 3 percentile). Thus the $2 \%$ more positive values, and the $2 \%$ more negative values were considered as candidate regions to have been targeted by selection, and established the corrected confidence limits of the distribution. For comparison, we used the theoretical distribution proposed by Tajima [30] to define the theoretical confidence limits. Significance of the difference in proportion of invariable windows between $S$. carpocapsae and $C$. briggsae was assessed with a $X^{2}$ test in a $2 \times 2$ table. The differences in theta and Tajima's $\mathrm{D}$ averages were assessed by $t$-test and a Wilcoxon (W) test. The difference in the distribution of $\mathrm{D}$ values was assessed by the nonparametric KolmogorovSmirnov (K-S) test.

\section{Selection in differentially expressed proteins}

Shotgun proteomics data from nematodes induced with insect tissues and from controls without induction were generated previously [12]. In brief, IJ nematodes were induced with either haemolymph or intestine of Galleria mellonella for 4 hours. Nematodes were ground in liquid nitrogen and used to extract total soluble proteins. Shotgun proteomics was done fractioning $200 \mu \mathrm{l}$ of the total protein extract. Thirty $\mu \mathrm{g}$ of protein from each fraction were then analysed by LC-MS/MS using a Thermo Scientific QExactive Orbitrap MS spectrometer in conjunction with a Proxeon Easy-nLC II HPLC (Thermo Scientific) and a source Proxeon nanospray using a reverse phase column. The MS/MS spectra were acquired using the TOP15 method following the equipment manufacturer's instructions. All analyses were run in duplicate, including treatment samples and controls [12]. With this data, Rougon-Cardoso et al. [12] conducted a qualitative analysis in which those proteins that were expressed in the samples and absent (below the detection level) in the controls, or vice versa, were detected. In the present study, using the same data, we conducted a label-free quantitative analysis, in which those proteins expressed only in the samples or the controls were excluded. Raw files of every fraction of the samples were processed using MaxQuant v 1.5.2.8 [61, 62] for protein identification and quantification. For identification of proteins, a false discovery rate of $1 \%$ at the peptide and protein level was used. The average absolute mass deviation was 0.2 parts per million (p.p.m.). For protein quantification, we used intensity based absolute quantification, or iBAQ [63]. Proteins amounts were calculated as the sum of all peptide peak intensities divided by the number of theoretically observable tryptic peptides. Data analysis was performed with Microsoft Office Excel and Perseus v.1.5.1.6 [64]. Differential expression analysis was performed using only proteins observed in the two replicates per condition, using $t$-test analyses and a False Discovery Rate (FDR) of $5 \%$. The results of the qualitative analysis done in
[12] were combined with the results of the quantitative label-free analysis described above.

The total list of differentially expressed proteins were contrasted against the list of genes with signatures of selection from both the interspecific and the intraspecific analyses, to identify the number of genes with expression data having also evolutionary data. From these genes, we counted the number of genes showing specific signatures of selection in both the differentially expressed and non-differentially expressed genes. These values were compared against each other and against the global analysis (inter and intraspecific). The significance of these differences were assessed by Fisher's exact tests in $2 \times 2$ tables.

\section{Functional annotation and enrichment analyses}

The association of genes to gene ontology (GO) terms (functional annotation) and enrichment of GO categories in genes with signatures of selection were performed with Blast2GO with a Fisher's exact test [65]. For the enrichment tests, we assessed if in genes with signatures of selection there were overrepresented GO terms in comparison to the genes without signs of selection in each analysis. In this way, we compared the associated GO terms found among genes with signatures of positive selection against the associated GO terms found in the rest of the analysed orthologue genes. In addition, GO terms in genes associated with windows with significant Tajima's D values were contrasted with the remaining genes in the genome.

\section{Genetic Distances}

Genome sequences were aligned gene by gene and concatenated for S. carpocapsae and C. briggsae strains. Nucleotide substitution models were estimated with jModelTest v. 2.1.3 [66], and the best model under the Bayesian information criterion (BIC) was chosen (Additional file 12). Alignments were transformed into phylip format with Clustalw2 v. $2.1[45,46]$, and pairwise maximum likelihood distances were estimated between strains with Tree-puzzle [67].

\section{Additional files}

Additional file 1: Functional annotation of S. carpocapsae genes with sites evolving under positive selection. Donut chart showing the $\mathrm{GO}$ term distribution at level 4 for biological process (BP), molecular function (MF), and cellular component (CC). GO analysis was performed using Blast2GO [65]. (PDF $458 \mathrm{~kb})$

Additional file 2: GO Distribution by Level 4 of S. carpocapsae genes with sites evolving under positive selection. (XLSX $20 \mathrm{~kb}$ )

Additional file 3: Enriched $\mathrm{GO}$ terms in the genes with sites under positive selection in nematode clade IV. (XLSX $13 \mathrm{~kb}$ )

Additional file 4: Enriched $\mathrm{GO}$ terms in the genes with sites under positive selection in nematode clade V. (XLSX $14 \mathrm{~kb}$ ) 
Additional file 5: Over-represented unique GO terms in genes with sites under positive selection. $a-b$, enriched $G O$ terms by lifestyle and $d-h$ by species. a, parasites from clade IV; $b$ parasites from clade $V ; c$, free living in clade IV; d Steinernema carpocapsae; e, Strongyloides ratti; f, Panagrellus redivivus; g, Heterorhabditis bacteriophora; h, Haemonchus contortus. Biological process in green, molecular function in blue, and cellular component in yellow. Enrichment analyses were performed with Blast2GO with a Fisher's exact test [65]. (PDF $213 \mathrm{~kb}$ )

Additional file 6: Steinernema carpocapsae protein coding genes included in windows with significant Tajima's D values. (XLSX $71 \mathrm{~kb}$ )

Additional file 7: Functional annotation of $S$. carpocapsae genes in windows with significant Tajima's D value. Donut chart showing the GO term distribution at level 4 for biological process (BP), molecular function (MF), and cellular component (CC) of the genes in windows with significant Tajima's D value. GO analysis was performed using Blast2GO [65]. (PDF $482 \mathrm{~kb}$ )

Additional file 8: GO Distribution by Level 4 of Steinernema carpocapsae protein coding genes included in windows with significant Tajima's $D$ values. (XLSX $33 \mathrm{~kb}$ )

Additional file 9: Differentially expressed proteins in S. carpocapsae infective juveniles induced with insect tissues. (XLSX $131 \mathrm{~kb}$ )

Additional file 10: Non-differentially expressed proteins in S. carpocapsae infective juveniles induced with insect tissues. (XLSX $232 \mathrm{~kb}$ )

Additional file 11: Genes for differentially expressed proteins with sites under positive selection or significant Tajima's D values. (XLSX $85 \mathrm{~kb}$ )

Additional file 12: Matrices of Maximum Likelihood distances between the analysed strains of S. carpocapsae and C. briggsae. (XLSX $12 \mathrm{~kb}$ )

\section{Acknowledgements}

Clarisse, a script for massive scans of positive selection using PAML, was developed and kindly provided by Victor Villa Moreno, from the Laboratorio de la Diversidad Biomolecular from Langebio, Cinvestav, under the direction of Dr. Mauricio Carrillo-Tripp. Christian Martinez provided bioinformatics technical help. We thank Alexander Loannidis and Sean M. Rovito for language editing. Two anonymous reviewers helped us to interpret $\mathrm{dN} / \mathrm{dS}$ values from parasitic branches and the enrichment of immune response $\mathrm{GO}$ terms.

\section{Funding}

The research leading to these results has received funding from FOMIXHidalgo (Fomix-Hgo-2008-C01-97032), and from the People Programme (Marie Curie Actions) of the European Union's Seventh Framework Programme FP7/ 2007/2013/ under REA grant agreement n 612583. MFP, MVE, EGO, and JNGCh received CONACYT fellowships for Master and/or Ph.D. studies (Reg. No. 219899; 262815, 746997, and 262962, respectively).

\section{Availability of data and materials}

Genome sequences of Steinernema carpocapsae strains generated during the current study are available in the NCBI GenBank, under the BioProject ID\# PRJNA351254, and BioSample accessions: SAMN05952344, SAMN05952345, SAMN05952346, and SAMN05952347.

\section{Authors' contributions}

MFP, RM, designed the study; MFP, conducted experiments; MVE, EGO developed Massive Tajima program; MFP, MVE, EGO, HERA, JNGCh, RM, analysed data; NS, contributed materials, RM, contributed materials and reagents; MFP, RM, wrote the paper. All authors reviewed and approved the manuscript.

\section{Competing interests}

The authors declare that they have no competing interests.

\section{Publisher's Note}

Springer Nature remains neutral with regard to jurisdictional claims in published maps and institutional affiliations.

\section{Author details}

'Laboratorio Nacional de Genómica para la Biodiversidad, Unidad de Genómica Avanzada, Centro de Investigación y de Estudios Avanzados del
Instituto Politécnico Nacional, Km 9.6 Libramiento Norte Carretera Irapuato León, Irapuato, Guanajuato, Mexico. ${ }^{2}$ CIRN/Departamento de Biologia, Universidade dos Açores, Rua Mãe de Deus, 13, 9500-321 Ponta Delgada, S. Miguel - Açores, Portugal.

Received: 28 October 2016 Accepted: 13 March 2017

Published online: 26 April 2017

\section{References}

1. Platt HM. Foreword. In: Lorenzen S, editor. The Phylogenetic Systematics of Free-living Nematodes. London: The Ray Society; 1994. p. i-ii.

2. Coghlan A. Nematode Genome Evolution. In: WormBook (ed. The C. elegans Research Community) 2005. http://www.wormbook.org.

3. Blaxter ML, De Ley P, Garey JR, Liu LX, Scheldeman P, Vierstraete A, Vanfleteren JR, Mackey LY, Dorris M, Frisse LM, Vida JT, Thomas WK. A molecular evolutionary framework for the phylum Nematoda. Nature. 1998;392:71-5.

4. Mitreva M, Blaxter M, Bird DM, McCarter JP. Comparative genomics of nematodes. Trends Genet. 2005;21(10):573-81.

5. Blaxter M, Koutsovoulos $\mathrm{G}$. The evolution of parasitism in Nematoda. Parasitology. 2015;142:S26-39.

6. Hunt VL, Tsai IJ, Coghlan A, Reid AJ, Holroyd N, Foth BJ, Tracey A, Cotton JA, Stanley EJ, Beasley H, Bennett HM, Brooks K, Harsha B, Kajitani R, Kulkarni A, Harbecke D, Nagayasu E, Nichol S, Ogura Y, Quail MA, Randle N, Xia D, Brattig NW, Soblik H, Ribeiro DM, Sanchez-Flores A, Hayashi T, Itoh T, Denver DR, Grant W, Stoltzfus JD, Lok JB, Murayama H, Wastling J, Streit A, Kikuchi T, Viney M, Berriman M. The genomic basis of parasitism in the Strongyloides clade of nematodes. Nat Genet. 2016;48:299-307. doi:10.1038/ng.3495.

7. Poinar GO. Origins and phylogenetic relationships of the entomophilic rhabditis, Heterorhabditis and Steinernema. Fundam Appl Nematol. 1993; 16(4):333-8.

8. Murfin KE, Dillman AR, Foster JM, Bulgheresi S, Slatko BE, Sternberg PW, Goodrich-Blair H. Nematode-bacterium symbioses-cooperation and conflict revealed in the "Omics" age. Biol Bull. 2012;223:85-102.

9. Peña JM, Carrillo MA, Hallem EA. Variation in the Susceptibility of Drosophila to Different Entomopathogenic Nematodes. Infect Immun. 2015;83(3):1130-8.

10. Goodrich-Blair H. They've got a ticket to ride: Xenorhabdus nematophilaSteinernema carpocapsae symbiosis. Curr Opin Microbiol. 2007;10:225-30.

11. Dillman AR, Macchietto M, Porter CF, Rogers A, Williams B, Antoshechkin I, Lee MM, Goodwin Z, Lu X, Lewis EE, Goodrich-Blair H, Stock SP, Adams BJ, Sternberg PW, Mortazavi A. Comparative genomics of Steinernema reveals deeply conserved gene regulatory networks. Genome Biol. 2015;16:1-21.

12. Rougon-Cardoso DA, Flores-Ponce M, Ramos-Aboites HE, Martinez-Guerrero CE, Hao Y-J, Cunha L, Rodríguez-Martinez JA, Ovando-Vázquez C, BermúdezBarrientos JR, Abreu-Goodger C, Chavarria-Hernández N, Simões N, Montiel $\mathrm{R}$. The genome, transcriptome, and proteome of the nematode Steinernema carpocapsae: evolutionary signatures of a pathogenic lifestyle. Sci Rep. 2016:6:37536

13. Nielsen R. Molecular signatures of natural selection. Annu Rev Genet. 2005; 39:197-218.

14. Aguileta G, Refregier G, Yockteng R, Fournier E, Giraud T. Rapidly evolving genes in pathogens: methods for detecting positive selection and examples among fungi, bacteria, viruses and protists. Infect Genet Evol. 2009:9:656-70.

15. Woolhouse ME, Webster JP, Domingo E, Charlesworth B, Levin BR. Biological and biomedical implications of the co-evolution of pathogens and their hosts. Nat Genet. 2002:32(4):569-77.

16. Kosiol C, Vinar T, da Fonseca RR, Hubisz MJ, Bustamante CD, Nielsen R, Siepel A. Patterns of Positive Selection in Six Mammalian Genomes. PLoS Genet. 2008;4(8):e1000144. doi:10.1371/journal.pgen.1000144.

17. Dobon A, Bunting DC, Cabrera-Quio LE, Uauy C, Saunders DG. The hostpathogen interaction between wheat and yellow rust induces temporally coordinated waves of gene expression. BMC Genomics. 2016:17(1):380. doi:10.1186/s12864-016-2684-4.

18. Ellegren H, Galtier N. Determinants of genetic diversity. Nat Rev Genet. 2016; 17(7):422-33. doi:10.1038/nrg.2016.58

19. Harris TW, Antoshechkin I, Bieri T, Blasiar D, Chan J, Chen WJ, De La Cruz N, Davis P, Duesbury M, Fang R, Fernandes J, Han M, Kishore R, Lee R, Müller HM, Nakamura C, Ozersky P, Petcherski A, Rangarajan A, Rogers A, Schindelman G, Schwarz EM, Tuli MA, Van Auken K, Wang D, Wang X, Williams G, Yook K, Durbin R, Stein LD, Spieth J, Sternberg PW. WormBase: a comprehensive resource for nematode research. Nucleic Acids Res. 2010;38:D463-7. doi:10.1093/nar/gkp952. 
20. Holterman M, van der Wurff A, van den Elsen $S$, van Megen $H$, Bongers $T$, Holovachov O, Bakker J, Helder J. Phylum-wide analysis of SSU rDNA reveals deep phylogenetic relationships among nematodes and accelerated evolution toward crown clades. Mol Biol Evol. 2006;23:1792-800.

21. Yang Z. Likelihood ratio test for detecting positive selection and application to primate lysozyme evolution. Mol Biol Evol. 1998;15(5):568-73.

22. Yang Z. Maximum Likelihood Estimation on Large Phylogenies and Analysis of Adaptive Evolution in Human Influenza Virus A. J Mol Evol. 2000;51:423-32. doi:10.1007/s002390010105

23. Yang Z, Nielsen R. Synonymous and nonsynonymous rate variation in nuclear genes of mammals. J Mol Evol. 1998;46:409-18.

24. Yang Z, Nielsen R. Codon-substitution models for detecting molecular adaptation at individual sites along specific lineages. Mol Biol Evol. 2002;19:908-17.

25. Zhang J, Nielsen R, Yang Z. Evaluation of an improved branch-site likelihood method for detecting positive selection at the molecular level. Mol Biol Evol. 2005;22:2472-9.

26. Yang Z. PAML 4: phylogenetic analysis by maximum likelihood. Mol Biol Evol. 2007;24:1586-91.

27. Jones JT, Moens M, Mota M, Li H, Kikuchi T. Bursaphelenchus xylophilus: opportunities in comparative genomics and molecular host-parasite interactions. Mol Plant Pathol. 2008:9:357-68. doi:10.1111/j.1364-3703.2007.00461.x.

28. Dierking K, Polanowska J, Omi S, Engelmann I, Gut M, Lembo F, Ewbank JJ, Pujol N. Unusual regulation of a STAT protein by an SLC6 family transporter in C. elegans epidermal innate immunity. Cell Host Microbe. 2011;9(5):425-35.

29. Thomas CG, Wang W, Jovelin R, Ghosh R, Lomasko T, Trinh Q, Kruglyak L, Stein LD, Cutter AD. Full-genome evolutionary histories of selfing, splitting, and selection in Caenorhabditis. Genome Res. 2015;25:667-78. doi:10.1101/ gr.187237.114.

30. Tajima F. Statistical method for testing the neutral mutation hypothesis by DNA polymorphism. Genetics. 1989;123:585-95.

31. Nei M, Suzuki Y, Nozawa M. The Neutral Theory of Molecular Evolution in the Genomic Era. Annu Rev Genom Hum G. 2010;11:265-89.

32. Galtier N, Depaulis F, Barton NH. Detecting bottlenecks and selective sweeps from DNA sequence polymorphism. Genetics. 2000;155(2):981-7.

33. Gaugler R. Entomopathogenic nematology. New Jersey: CABI Publishing; 2002.

34. Gasser RB, Zhu X, McManus DP. NADH dehydrogenase subunit 1 and cytochrome c oxidase subunit I sequences compared for members of the genus Taenia (Cestoda). Int J Parasitol. 1999;29(12):1965-70.

35. Kraemer BC, Schellenberg GD. SUT-1 enables tau-induced neurotoxicity in C. elegans. Hum Mol Genet. 2007;16(16):1959-71.

36. Forst S, Clarke D. Bacteria-nematode symbiosis. In: Gaugler R, editor. Entomopathogenic nematology. New York: CABl; 2002. p. 57-77.

37. Parkinson J, Mitreva M, Whitton C, Thomson M, Daub J, Martin J, Schmid R, Hall N, Barrell B, Waterston RH, McCarter JP, Blaxter ML. A transcriptomic analysis of the phylum Nematoda. Nat Genet. 2004;36(12):1259-67. doi:10.1038/ng1472.

38. Kimura M. Evolutionary rate at the molecular level. Nature. 1968;217:624-6.

39. King JL, Jukes TH. Non-Darwinian Evolution. Science. 1969;164:788-97.

40. Roux J, Privman E, Moretti S, Daub JT, Robinson-Rechavi M, Keller L. Patterns of positive selection in seven ant genomes. Mol Biol Evol. 2014;31(7):1661-85.

41. Stajich JE, Hahn MW. Disentangling the Effects of Demography and Selection in Human History. Mol Biol Evol. 2005;2(1):63-73. doi:10.1093/molbev/msh252.

42. Pybus M, Luisi P, Dall'Olio GM, Uzkudun M, Laayouni H, Bertranpetit J, Engelken J. Hierarchical boosting: a machine-learning framework to detect and classify hard selective sweeps in human populations. Bioinformatics. 2015;31(24):3946-52. doi:10.1093/bioinformatics/btv493.

43. Schmidt D, Pool J. The effect of population history on the distribution of the Tajima's D statistic. New York: Cornell University Press; 2002. http:// wolfweb.unr.edu/ drschmidt/TajimasD.pdf.

44. Li L, Stoeckert CJ, Roos DS. OrthoMCL: identification of ortholog groups for eukaryotic genomes. Genome Res. 2003;13:2178-89.

45. Thompson JD, Higgins DG, Gibson TJ. CLUSTAL W: improving the sensitivity of progressive multiple sequence alignment through sequence weighting, position-specific gap penalties and weight matrix choice. Nucleic Acids Res. 1994;22:4673-80.

46. Larkin MA, Blackshields G, Brown NP, Chenna R, McGettigan PA, McWilliam H, Valentin F, Wallace IM, Wilm A, Lopez R, Thompson JD, Gibson TJ, Higgins DG. Clustal W and Clustal X version 2.0. Bioinformatics. 2007;23:2947-8.

47. Castresana J. Selection of conserved blocks from multiple alignments for their use in phylogenetic analysis. Mol Biol Evol. 2000;17:540-52.
48. Darriba D, Taboada GL, Doallo R, Posada D. ProtTest 3: fast selection of best-fit models of protein evolution. Bioinformatics. 2011;27:1164-5.

49. Guindon S, Gascuel O. A simple, fast, and accurate algorithm to estimate large phylogenies by maximum likelihood. Syst Biol. 2003;52:696-704.

50. Wernersson R, Pedersen AG. RevTrans: multiple alignment of coding DNA from aligned amino acid sequences. Nucleic Acids Res. 2003;31:3537-9.

51. Sambrook J, Fritsch EF, Maniatis T. Molecular cloning: a laboratory manual. 2nd ed. New York: Cold Spring Harbor Laboratory Press; 1989.

52. Li H, Durbin R. Fast and accurate short read alignment with BurrowsWheeler Transform. Bioinformatics. 2009;25:1754-60.

53. Li H. Aligning sequence reads, clone sequences and assembly contigs with BWA-MEM. 2013;arXiv:1303.3997 [http://arxiv.org/abs/1303.3997].

54. Stein LD, Bao Z, Blasiar D, Blumenthal T, Brent MR, Chen N, Chinwalla A, Clarke L, Clee C, Coghlan A, Coulson A, D'Eustachio P, Fitch DH, Fulton LA, Fulton RE, Griffiths-Jones S, Harris TW, Hillier LW, Kamath R, Kuwabara PE, Mardis ER, Marra MA, Miner TL, Minx P, Mullikin JC, Plumb RW, Rogers J, Schein JE, Sohrmann M, Spieth J, Stajich JE, Wei C, Willey D, Wilson RK, Durbin $\mathrm{R}$, Waterston $\mathrm{RH}$. The genome sequence of Caenorhabditis briggsae: a platform for comparative genomics. PLoS Biol. 2003;1(2):E45.

55. Li H, Handsaker B, Wysoker A, Fennell T, Ruan J, Homer N, Marth G, Abecasis G, Durbin R. 1000 Genome Project Data Processing Subgroup. The Sequence alignment/map (SAM) format and SAMtools. Bioinformatics. 2009;25:2078-9.

56. Li H. A statistical framework for SNP calling, mutation discovery, association mapping and population genetical parameter estimation from sequencing data. Bioinformatics. 2011;27(21):2987-93.

57. Danecek P, Auton A, Abecasis G, Albers CA, Banks E, Depristo MA Handsaker RE, Lunter G, Marth GT, Sherry ST, McVean G, Durbin R. 1000 Genomes Project Analysis Group. The variant call format and VCFtools. Bioinformatics. 2011;27(15):2156-8. doi:10.1093/bioinformatics/btr330.

58. The International HapMap Consortium. A haplotype map of the human genome. Nature. 2005;437:1299-320. doi:10.1038/nature04226.

59. Nei M, Miller JC. A simple method for estimating average number of nucleotide substitutions within and between populations from restriction data. Genetics. 1990;125(4):873-9.

60. Hamilton MB. Population genetics. West Sussex: Wiley-Blackwell; 2009

61. Cox J, Mann M. MaxQuant enables high peptide identification rates, individualized p.p.b.-range mass accuracies and proteome-wide protein quantification. Nat Biotechnol. 2008;26:1367-72.

62. Cox J, Hein MY, Luber CA, Paron I, Nagaraj N, Mann M. Accurate Proteomewide Label-free Quantification by Delayed Normalization and Maximal Peptide Ratio Extraction, Termed MaxLFQ. Mol Cell Proteomics. 2014;13:2513-26.

63. Schwanhäusser B, Busse D, Li N, Dittmar G, Schuchhardt J, Wolf J, Chen W, Selbach M. Global quantification of mammalian gene expression control. Nature. 2011:473:337-42.

64. Tyanova S, Temu T, Sinitcyn P, Carlson A, Hein MY, Geiger T, Mann M, Cox J. The Perseus computational platform for comprehensive analysis of (prote)omics data. Nat Methods. 2016;13(9):731-40. doi:10.1038/nmeth.3901.

65. Conesa A, Götz S, García-Gómez JM, Terol J, Talón M, Robles M. Blast2GO: a universal tool for annotation, visualization and analysis in functional genomics research. Bioinformatics. 2005;21(18):3674-6.

66. Darriba D, Taboada GL, Doallo R, Posada D. jModelTest 2: more models, new heuristics and parallel computing. Nat Methods. 2012;9(8):772.

67. Schmidt HA, Strimmer K, Vingron M, von Haeseler A. TREE-PUZZLE: maximum likelihood phylogenetic analysis using quartets and parallel computing. Bioinformatics. 2002;18:502-4.

\section{Submit your next manuscript to BioMed Central and we will help you at every step:}

- We accept pre-submission inquiries

- Our selector tool helps you to find the most relevant journal

- We provide round the clock customer support

- Convenient online submission

- Thorough peer review

- Inclusion in PubMed and all major indexing services

- Maximum visibility for your research

Submit your manuscript at www.biomedcentral.com/submit 